\title{
Análise do Uso e Ocupação do Solo relacionado À Expensão do Aeroporto Internacional de GoIÂNIA Por meio de Classificação Segmentada de Máxima Verossimilhança
}

\author{
Analysis of Land Use and Occupation Related to the Expansion of \\ the Goiânia Internacional Airport through the Maximum Likelihood \\ Classification (MLC) Method
}

\author{
(iD) 0 \\ Cristiano Farias de Almeida \\ Universidade Federal de Goiás, Goiânia, GO, Brasil. \\ cristianofarias@ufg.br \\ iD 0 \\ Sara Santos de Almeida \\ Universidade Federal de Goiás, Goiânia, GO, Brasil. \\ almeidasarag@discente.ufg.br \\ Michelle Carvalho Galvão da Silva Pinto Bandeira \\ Universidade Federal de Goiás, Goiânia, GO, Brasil. \\ michelle.galvao@ufg.br
}

\begin{abstract}
Resumo
O crescimento da população é um dos principais fatores que contribuem para o desenvolvimento de modos de transportes mais eficientes. Ao longo das décadas, vários autores tentaram desenvolver conceitos explicativos sobre este fato. $\mathrm{O}$ aumento da demanda pode ser diferente em função do investimento no modo de transporte, da mesma forma que o transporte pode alterar o uso do solo e, este por sua vez pode influenciar o transporte. Nesse sentido, este artigo tem como objetivo analisar as alterações ocorridas pela ampliação e a mudança do terminal de passageiros do Aeroporto Internacional de Goiânia - Santa Genoveva (SBGO) geraram no uso do solo local. No desenvolvimento do trabalho foi usado um método indireto, por meio de Sistema de Informação Geográfica (SIG), denominado de técnica de Classificação Segmentada de Máxima Verossimilhança (MAXVER), que resulta em mapas temáticos para tal análise. Os resultados mostraram-se eficientes na análise qualitativa e foi possível constatar o aumento de áreas comerciais, industriais e também de áreas verdes.
\end{abstract}

Palavras-chave: Uso do Solo. Aeroporto. Método de Classificação de Máxima Verossimilhança. 


\section{Abstract}

Population growth is one of the main factors contributing to the development of transport modes mor efficient. Over the decades several authors have tried to bring more explanatory concepts about this fact. The increase in demand may be different depending on the investment in the mode of transportation, in the same way that transport may change land use and land use, this in turn may influence transport. Due to this, this paper aims to analyze the changes occurred by the expansion and the change of the passenger terminal of the Santa Genoveva International Airport (SBGO) in Goiannia city generated in the local land. An indirect method was used in the development of the this study, by means of Geographic Information System (GIS), called technique of Maximum Likelihood Classification (MAXVER), which results in thematic maps for such analysis. The results were efficient in the qualitative analysis and it was possible to verify the increase of commercial, industrial and green areas.

Keywords: : Land Use. Airport. Service Level. Method of Maximum Likelihood Classification.

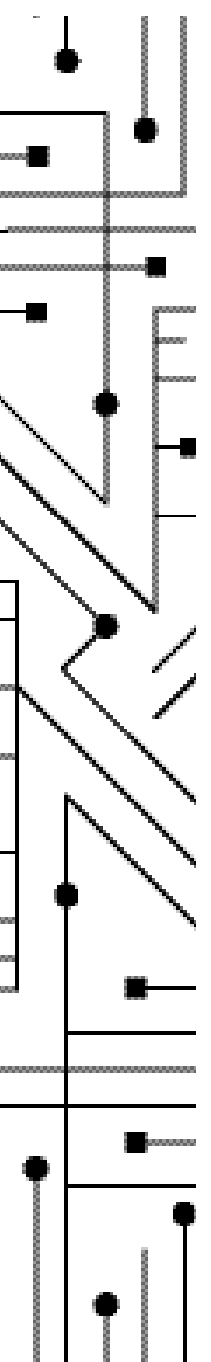




\section{Introdução}

Uso do solo e transporte são elementos que não podem ser dissociados, uma vez que a influência que ocorre entre eles é mútua. A relação causal entre a disposição do uso do solo e os sistemas de transportes ditam a organização e o comportamento da sociedade, no que tangem tanto a mobilidade urbana quanto o desenvolvimento socioeconômico.

Kawamoto (1994) afirma que o sistema de transportes é "um conjunto de pares (veículos, vias, terminais) que se interagem de modo a promover deslocamento espacial de pessoas e mercadorias, segundo vontade dos usuários, programação dos operadores, e regras estabelecidas."

Por outro lado, o termo 'sistema' está incorporado na organização e funcionamento das mais diversas ciências. As teorias que melhor definem o fenômeno de transportes, é de cunho humano e social, como um todo são as de abordagem filosófico-teórico (MAGALHÃES; ARAGÃO; YAMASHITA, 2014).

O uso do solo é um sistema correlacionado no qual a escolha da implantação de um estabelecimento é realizada de acordo com o quanto sua posição irá influenciar espacialmente no local e quais outros padrões de uso existentes vão influenciálo (CAMPOS, 2013). O que compreende que a distribuição espacial existente influencia no padrão de uso dos sistemas de transportes, assim como tal interfere no desenvolvimento do local.

Tratando-se mais especificamente do transporte aéreo, devido as dimensões físicas e a dinâmica das atividades geradas por um aeroporto, observa-se que o impacto causado no entorno é bastante significativo (Ashford et al., 2011). Por ser uma infraestrutura de grande complexidade é necessário que se considere a sua atratividade, ou seja, a influência geográfica de atividades e serviços desenvolvidos ao seu redor, os fatores que determinaram a expansão e o impacto causado nas alterações do entorno aeroportuário. 
Existem várias denominações que definem aeroportos, algumas sob o ponto de vista econômico. Kasarda e Lindsay (2012), por exemplo, definem Aerotrópole uma estrutura urbana que visa alocar empreendimentos voltados para suprir a demanda do aeroporto, que o adota como centro de todo o planejamento em um raio de 30 quilômetros. Uma Aerotrópole tem o incentivo à abertura e funcionamento com vínculo econômico e adjunto ao modo aéreo, garantindo mobilidade, logística, renda, competitividade e emprego.

A importância da aviação civil na vida moderna fez com que o aeroporto ganhasse influência no território urbano adjacente ao sítio e além, em um contexto regional, alterando sua maneira de atuação na vida urbana, de assuntos puramente aeronáuticos, como tráfego aéreo, para oportunidades de negócios e empreendimentos imobiliários (GÜLLER; GÜLLER, 2001). Um exemplo da atratividade que o aeroporto exerce no seu entorno é a instalação de diversos tipos de empreendimentos, que podem servir para as atividades diretas e indiretas da infraestrutura aeroportuária. A exemplo, podem ser citados hotéis, prédios comerciais, conjuntos habitacionais, centros logísticos de produtos e serviços entre outros. Todas essas instalações e atividades geradas podem medir o impacto positivo que um aeroporto pode causar (GÜLLER; GÜLLER, 200).

Essa mudança dos domínios do aeroporto aconteceram em decorrência, fundamentalmente, da importância da aviação civil para a vida urbana, transportando pessoas às regiões mais longínquas do globo, movendo bens e produtos pelas cadeias de valor globais e conectando todos os tipos de informações e conhecimentos para a vida moderna, transformando aeroportos em motores da economia contemporânea, e complementarmente porque a receita aeronáutica não mais supre as despesas da complexidade da infraestrutura aeroportuária atual (GÜLLER; GÜLLER, 2001; KASARDA; LINDSAY, 2012).

Por outro lado, "o mau uso do solo no entorno do aeródromo, como a construção de edificações que venham a interferir na aproximação de aeronaves, ou a existência 
de lixões nas proximidades do sítio aeroportuário, pode trazer risco à operação no aeródromo, levando inclusive à imposição de restrições operacionais."(ANAC, 2021).

Assim, este artigo tem como objetivo compreender e analisar as alterações do uso do solo no entorno do aeroporto Santa Genoveva após sua expansão pode contribuir com a gestão aeroportuária e com o melhor desenvolvimento orgânico da cidade de Goiânia,GO. No desenvolvimento do estudo foi utilizado o Sistema de Informação Geográfica (SIG) como ferramenta de análise espacial da região a ser estudada, juntamente com a Classificação Segmentada de Máxima Verossimilhança (MAXVER), de modo a verificar as alterações ocorridas.

Este trabalho está estruturado em mais quatro seções, a saber: descrição do sistema de transporte e uso do solo; apresentação das principais características da ferramenta da Máxima Verossimilhança (MAXVER); análise do uso do solo na área de influência do aeroporto Santa Genoveva; e finalmente, as conclusões do artigo.

5

\section{Sistema de Transporte e Uso do Solo}

De acordo com Bunge (1979 apud MAGALHÃES 2014, p.3) um sistema é composto por três características importantes: A-Composição, A-Ambiente e A-Estrutura, sendo o 'A', referente ao termo 'atômico' que dizer que envolve não só as partes, mas também cada item como um todo, que serão simplificadas a seguir. Composição seria o conjunto de todos as partes do sistema, que apresentam certa conexão entre si. Ambiente o conjunto de todas as coisas, que de certa forma incluídas no sistema, sofrem ação dos componentes. Estrutura o conjunto das conexões entre os componentes da Composição e suas relações com as coisas no Ambiente.

Como dito anteriormente, a relação uso do solo e transporte é causal, de forma que uma interfere na outra de maneira direta. No entanto, até por volta da década de 50, a visão da relação entre transporte e uso do solo era mais restrita, como afirmava Mitchell e Rapkin (1954) "diferentes tipos de uso do solo geram diferentes fluxos de tráfego". Ou seja, o tráfego dependia apenas do uso do solo. No entanto, 
com a evolução do conhecimento, em 1961, Wingo e Perloff complementam essa teoria, afirmando que "a influência entre transporte e uso do solo é mútua, ou seja, de interdepen-dência" (SANTOS, 2015).

A oferta de acessibilidade e mobilidade são requisitos de destaque nas áreas urbanas, as quais são totalmente afetadas pela relação transporte e uso do solo. A distribuição espacial de atividades soci-oeconômicas nos meios urbanos acabam funcionando como polos geradores de viagens, produzindo e atraindo viagens. E para que o acesso a estes locais exista, é preciso de sistemas de transporte que atendem às necessidades e demanda exigidas.

Vários estudos tentaram analisar o entorno do aeroporto e sua relação do uso do solo e o transporte aeroviário, com o objetivo de obter uma forma de analisar as áreas do entorno e a ocupação do solo. Como exemplos, tem-se os trabalhos de Walker e Stevens (2008), que fizeram um mapeamento das zonas de uso do solo no entorno aeroportuário de vinte aeroportos australianos, onde foi proposto uma classificação de zoneamento comum a todos os aeroportos. Adicionalmente, o trabalho de Janic (2016) apontou o uso residencial, de concentração de pessoas e atração de vida selvagem como os principais problemas encontrados em um estudo sobre incompatibilidade de uso do solo realizado no entorno de aeroportos dos Estados Unidos. Além dos aspectos de engenharia de transporte que afetam as necessidades espaciais para o alcance da capacidade, existem também os aspectos regulatórios de segurança operacional que precisam ser atendidos, conforme a RBAC n¹54 que define as condições de contorno de projetos de aeródromos (ANAC, 2019)

Segundo Fermisson et al. (2004), baseado em um projeto europeu chamado TRANSPLUS (TRANSport Planning, Land Use and Sustainability) realizado em 1999, a questão da mobilidade urbana vem sendo abordada sob a ótica de duas políticas principais: a de ordenamento físico (ou uso do solo) e a de transporte. A dissociação das políticas podem gerar falhas na definição de problemas que afetariam o processo de planejamento de transportes. A interação cíclica que explica a relação 


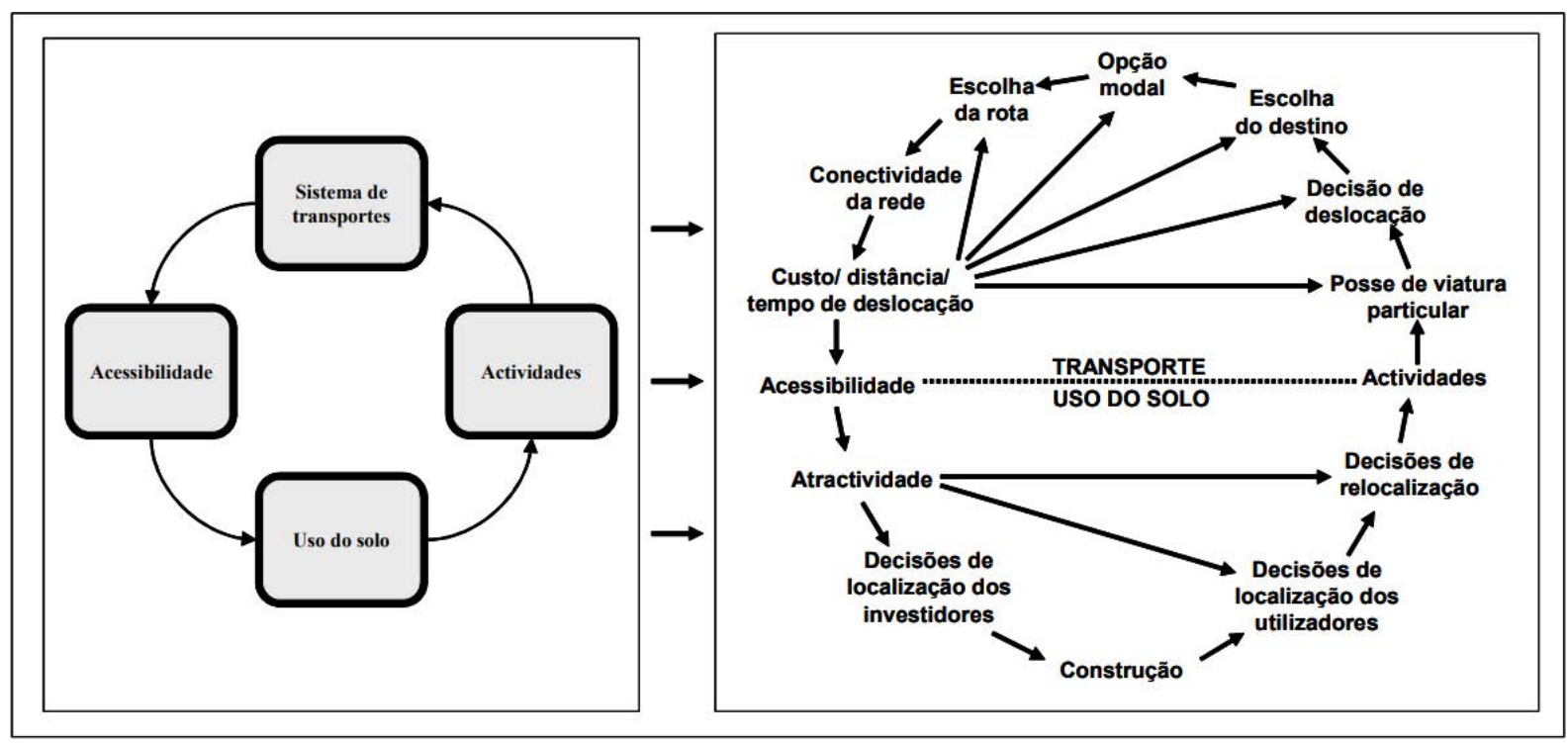

Figura 1- Interações elementares entre transporte e uso do solo. Fonte: Wegener e Fürst (1999) apud Fermisson et al. (2004).

De acordo com Fermisson et al. (2004), existem quatro componentes principais que caraterizam a interação transporte e uso do solo, como apresentado na Figura 1. Representando a realidade do estudo proposto, pode-se compreender que:

i) “A alocação espacial das diferentes categorias de uso do solo através de instrumentos de ordenamento físico, orienta e condiciona a localização das várias atividades humanas no território". Neste caso, pode ser considerado como parte importante desse arranjo espacial como exemplo o "Plano de Zona de Proteção dos Aeródromos (PBZPA), que impõe limites quanto à presença de edificações e outros objetos que venham a representar perigo ou risco às operações aéreas" (Portaria n 1141/GM5 de 08/12/1987) (ANAC, 2016).

ii) "A repartição desigual das atividades no território (induzida quer pelos instrumentos de ordenamento físico, quer pelos requisitos locacionais específicos de cada atividade) gera necessidades de interação espacial a que o sistema de transportes deverá dar resposta"(FERMISSON et al., 2004). Entende-se que para analisar o território do entorno aeroportuário deve-se considerar como aspecto principal a distribuição territorial de uso 
do solo, disponibilizando áreas para: a) ampliação do sítio aeroportuário; b) atividades comerciais/industriais relacionadas à indústria aeronáutica ou que de alguma maneira sejam impulsionados pela presença do aeroporto para a economia regional; c) Vias de conectividade entre o aeroporto e as demais áreas da cidade (principalmente com o centro urbano); e, d) diminuição dos impactos ambientais causados pelas operações de pouso e decolagem (FAA, 2009; GÜLLER; GÜLLER, 2001; JANIC, 2016)

iii) "A configuração espacial e o tipo de serviço oferecido pelo sistema de transporte definem os níveis de acessibilidade entre localizações, isto é, a maior ou menor facilidade com que as diferentes" localizações são fisicamente acessíveis (FERMISSON et al., 2004). A configuração espacial desejável para o território do entorno aeroportuário é um solo com uma distribuição equilibrada de usos que permitam áreas não construídas nas proximidades do sítio aeroportuário. Isto promove maior conforto ambiental em relação ao ruído aeronáutico, além de ocupações compatíveis para as atividades empresariais ligadas à indústria aeronáutica, assim como vias que possam garantir uma melhor acessibilidade com o centro gerador de demanda.

iv)A distribuição dos níveis de acessibilidade induz processos de valorização/ desvalorização locacionais diferenciados ao nível das várias parcelas do território, originando vocações distintas que devem ser refletidas nas diferentes formas de uso do solo proposta em planos de ordenamento (FERMISSON et al., 2004). Este item está relacionado ao planejamento do aeroporto, pois deve-se observar a expansão do aeroporto, que deve estabelecer a melhor relação entre a demanda estimada, o meio ambiente, o desenvolvimento da comunidade e dos outros meios de transporte (GÜLLER e GÜLLER, 2001). Adicionalmente, as diretrizes urbanas, ambientais e de acessibilidade devem ser priorizadas. 
De acordo com levantamento realizado em 2007 pelo Plano Aeroviário do Estado de São Paulo (PAESP), um Aeroporto pode ser classificado dentro de cinco classes existentes, conforme suas funções e o seu volume de tráfego: Aeroporto Internacional, Aeroporto Nacional, Aeroporto Regional, Aeroporto Local, Aeroporto Complementar.

Para que seja estabelecida a execução da Rede Estadual de Aeroportos é preciso atender as exigências da legislação aeronáutica relativas à construção, exploração, administração e proteção das unidades aeroportuárias e seus entornos. As principais diretrizes são do projeto do Aeródromo, ou seja, o órgão estadual e/ ou municipal, encarregado pela gestão dos Aeródromos tem a responsabilidade de elaborar os projetos seguindo as diretrizes constantes do Plano e as normas do projeto, a fim de atuar corretamente no dimensionamento e localização dos componentes aeroportuários (PAESP, 2007).

Uma delas é a aeroportuária, em que o planejamento feito no Brasil está agregado no contexto mundial por meio da adoção dos padrões requisitados pela International Civil Aviation Organization (ICAO). Tais orientações estão adaptadas às necessidades brasileiras nas diretrizes setoriais do Ministério Público da Defesa, na legislação do Plano Básico de Zona de Proteção de Aeródromos, da mesma forma que a legislação relativa à elaboração de projeto, construção, abertura ao tráfego, operação, manutenção e exploração de aeródromos.

\section{Classificação Segmentada De Máxima Verossimilhança (Maxver)}

Quando se trata de classificação de imagens, existem dois tipos: a nãosupervisionada e a supervisionada. A última é quando as classes são determinadas por quem está analisando, que é o caso da Máxima Verossimilhança (MAXVER). Este tipo de segmentação é um método estatístico utilizado para classificar pixel a pixel as regiões delimitadas. 
O algoritmo dessa classificação calcula as distribuições de probabilidade para as classes definidas, ligadas ao Teorema de Bayes, estimando se um pixel pertence a essa classe. Tais distribuições são apresentadas na forma de modelos multivariados. Para utilizar o algoritmo é preciso um número razoável de pixels para cada área de treinamento, chegando à determinação de uma matriz de covariância, de acordo com Richards e Jia (2006 apud Congedo, 2018). A função discriminante é dada pela equação (1).

$$
g k(x)=\ln p(C k)-12 \ln |\Sigma k|-12(x-y k) t \Sigma-1 k(x-y k)
$$

em que $C k$ : $\quad$ classe de ocupação do solo $k$;

$x$ : $\quad$ vetor de assinatura espectral de um pixel de imagem;

$p(C k)$ : probabilidade de que a classe correta seja $C k$;

$|\Sigma k|$ : determinante da matriz de covariância dos dados da classe $C k$;

$\sum_{k}^{-1}:$ inverso da matriz de covariância;

$y k$ : $\quad$ vetor de assinatura espectral da classe $k$.

Desta forma, tem-se a equação (2):

$$
x \in C k \Leftrightarrow g k(x)>g_{\mathrm{j}}(x) \forall k \neq \mathrm{j}
$$

Sendo possível determinar uma função discriminante que exclua pixels abaixo do valor da classificação, desde que obedeça a inequação (3).|

$$
g k(x)>T i
$$

Essa relação descrita por meio da inequação (3) pode ser vista graficamente por meio da Figura 2.

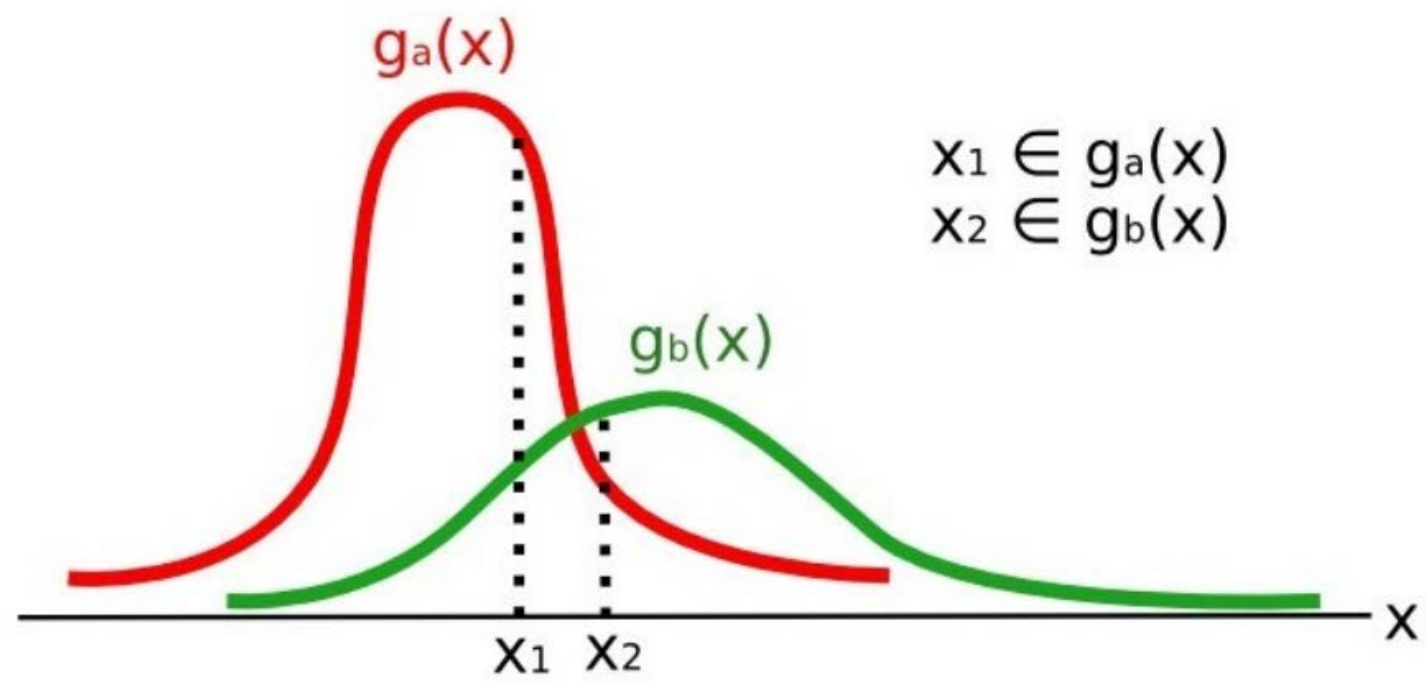

Figura 2- Exemplo da função de Máxima Verossimilhança.

Fonte: Congedo, 2018. 


\section{Metodologia da Pesquisa}

O enfoque metodológico dessa pesquisa é indireto e empírico. Por meio da observação da classificação feita pelo meio de imagens de sensoriamento remoto, adotou-se o estudo de caso para o Aeroporto Santa Genoveva.

\section{Área da Pesquisa}

Dentre os aeroportos existentes no Brasil, o Aeroporto Internacional de Goiânia - Santa Genoveva (SBGO), destaca-se com sua ótima localização diante da logística das rotas aéreas e do escoamento e recebimento dessa produção do País por estar localizado na região Centro-Oeste, recebendo o título de Internacional em agosto de 2020 (INFRAERO, 2020). A partir daí, o aeroporto foi autorizado a processar operações internacionais para os serviços aéreos públicos regulares e não regulares, incluindo táxi aéreo e aviação geral, e voos cargueiros de operadores que queiram ter a capital de Goiás como destino. Recentemente, o aeroporto foi concedido a uma empresa privada em um leilão feito pelo Governo Federal em abril do presente ano. $\mathrm{O}$ aeroporto foi concessionado à Companhia de Participações em Concessões (CPC), subsidiária do Grupo CCR, que atualmente administra diversas rodovias pelo País.

O aeroporto ocupa uma área de aproximadamente $3.967 .365,04 \mathrm{~m}^{2} \mathrm{e}$ está localizado na área urbana próximo ao centro de Goiânia, a cerca de 8 km de distância. Além disso, compreende cerca de 1,8\% na quantidade de decolagens de voos domésticos no Brasil, estando entre os 20 principais aeroportos brasileiros. $O$ maior valor é do Aeroporto Internacional de Guarulhos (GRU), com 10,9\%. Enquanto o Aeroporto de Guarulhos realiza em média 90.200 decolagens, o Aeroporto Santa Genoveva faz em média 14.693 decolagens, isso se tratando apenas de voos domésticos (ANAC, 2016). "Em 2016 foi inaugurado o novo terminal de passageiros com novas e modernas instalações em uma área construída de 34,1 mil m" (ANAC, 2016).

Segundo a Aviação Brasil (2018), os canais de inspeção passaram de quatro para sete. As esteiras de bagagem que antes eram três, sendo duas de 33 metros 
e uma com 27 metros, aumentaram as três para 36 metros cada. E os balcões de check-in de 30 sendo compostos por dois operadores por balcão passaram a ser 23 , com um operador por balcão. A ampliação contou também "com quatro pontes de embarque e estacionamento com 971 vagas. Com essa estrutura, Goiânia poderá receber até 6,5 milhões de passageiros por ano. Em 2015, a demanda foi de 3,31 milhões de viajantes" (INFRAERO, 2018). Ainda de acordo com a Infraero (2018), a obra do novo Aeroporto de Goiânia demorou mais de uma década para finalizar, e ao final, a área do terminal praticamente quadriplicou (Figuras 3 e 4).

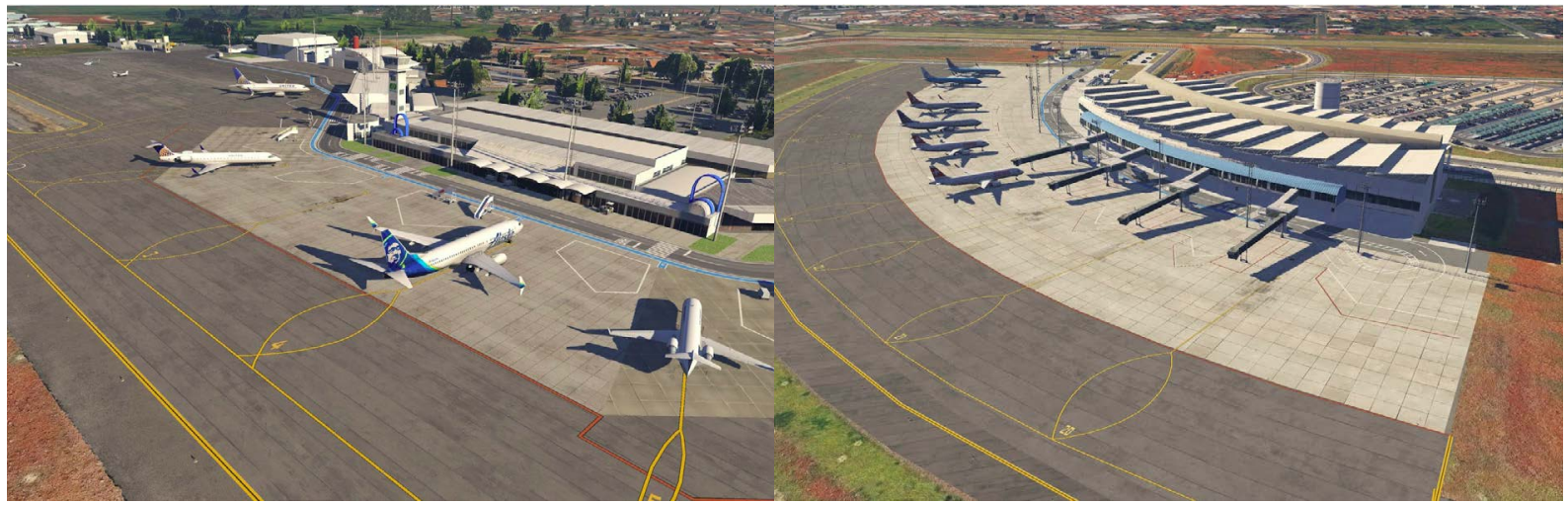

Figura 3-Terminal de Passageiros e Pátio de Aeronaves antes da expansão (à esquerda) e após a expansão (à direita). Fonte das imagens: https://axplane.blogspot.com/p/sbgo.

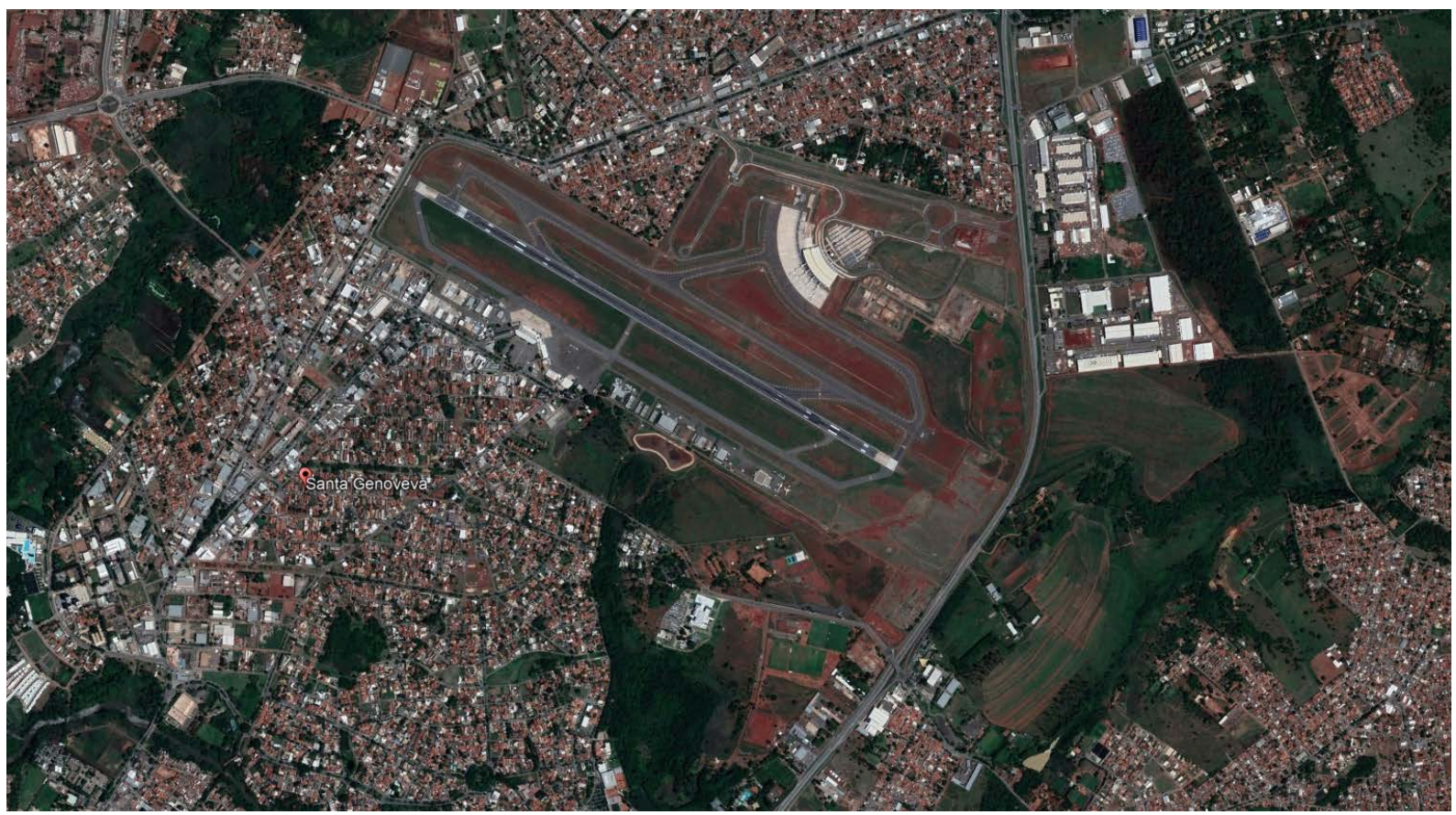

Figura 4 - Aeroporto Santa Genoveva após expansão em 2017 - Imagem Geral. Fonte: Google Earth (2018). 
Com a ampliação do aeroporto, houve melhorias no quesito acessibilidade, visto que antes não existiam elevadores e escadas rolantes. Maior capacidade de passageiros e visitantes e acessibilidade de vias ao estacionamento. Essa nova configuração promoveu maior número de serviços e produtos para o aeroporto. Consequentemente, a área de influência foi impactada por essa nova demanda e receitas não-aeronáuticas geradas. Outras configurações do aeroporto foram ampliadas como mostra a Tabela 1.

Tabela 1: Configurações do Aeroporto Santa Genoveva antes e depois da expansão.

\begin{tabular}{ccc} 
Características do Terminal & Anterior à Expansão & Após a Expansão \\
\hline Area do terminal de passageiros $\left(\mathrm{m}^{2}\right)$ & 7.571 & 34.100 \\
Capacidade de Passageiros (milhões) & 3,5 & 6,5 \\
Número de elevadores & - & 11 \\
Número de escadas rolantes & - & 4 \\
Vagas de estacionamento para veículos & 589 & 971 \\
Número de posições de paradas de Aeronaves & 6 & 10 \\
\hline
\end{tabular}

Fonte: Infraero (2018).

13

\section{Aplicação do Método}

A metodologia envolveu uma análise por método indireto, denominada por Imagem de Sensoriamento Remoto processadas em um Sistema de Informação Geográfica. Assim, foi realizado a Classificação Supervisionada do tipo pixel a pixel, por meio de um software de SIG chamado QGIS. Para a realização de tal atividade foi necessário usar o Google Earth, para extrair as imagens de satélite a serem utilizadas.

Inicialmente foi necessário definir a área de influência do aeroporto objeto de estudo, de forma a facilitar a coleta de dados, possibilitar a realização da Classificação Supervisionada e permitir a análise do uso do solo local. A área de influência do aeroporto definida foi apoiada na Lei Municipal de $\mathrm{N}^{\circ} 5212$, de 22 de dezembro de 1976 art $1^{\circ}$, a qual define a zona de influência do Aeroporto como:

"§ $2^{\circ}$ - A Zona Especial da Área de Influência do Aeroporto Santa Genoveva, criada pelo item III deste artigo, tem os seguintes limites: começa na confluência da Avenida João Leite com a Avenida Guatapara; segue pela Avenida Guatapara, Avenida Nazareth, Rua Goiás, Rua Santa Catarina, Rua Goiás, BR-153, Trecho A-B continuação da linha de divisa do loteamento do 
Setor Jaó com a área do Aeroporto Santa Genoveva, Trecho C-D, divisa do loteamento do Setor Jaó com o Aeroporto Santa Genoveva, Avenida Sucuri, Rua Jaó, Avenida Brasília, e Avenida João Leite até o ponto inicial."

Para este trabalho foi considerada a área de influência um pouco maior do que a Lei Municipal con-sidera, visto que o aeroporto pode gerar influência territorial superior a observada pelas delimitações legais, isto ocorre justamente por que o aeroporto é um polo gerador de viagens.

Uma vez definida a área de influência, foram selecionadas três imagens do aeroporto e seu entorno, para os anos de 2003, 2014 e 2017, para fazer as análises. Tal escolha foi feita com o intuito de analisar as alterações ao redor do aeroporto, bem como o uso do solo em sua área de influência, acompanhando o processo temporal de expansão do mesmo.

Por meio do QGIS as imagens selecionadas foram georreferenciadas de maneira a mapear o perímetro de uma área de acordo com o Sistema Geodésico Brasileiro, ou seja, registrar as imagens, cada uma de suas bandas, e de acordo com suas coordenadas. Isso permitiu a criação de arquivo em formato raster, necessário para a fazer classificação. Feito o georreferenciamento, foi necessário instalar um complemento chamado 'Semi-Automatic Classification Plugin'. Tal complemento permitiu recolher as amostras para serem classificadas.

A coleta de amostras foi feita desenhando-se polígonos que delimitam as áreas a serem analisadas, dividindo-as em grupos. $O$ treinamento consistiu em agrupar as áreas de pixels homogêneos, e poste-riormente classificados em: áreas residenciais, áreas industriais e comerciais, área verde, solo exposto, estradas pavimentadas e água (locais com água). As áreas residenciais e industriais foram caracterizadas por meio da diferença existente entre a cobertura das edificações, mostrados pela diferença de cor: telhas de barro e telhas de zinco, respectivamente.

Em sequência, foi determinado o algoritmo para realizar a Classificação Segmentada de Máxima Verossimilhança (MAXVER). Usando a ferramenta 'Classification Algorithm' foi selecionado 'Maximum Likelihood'. Tal processo é baseado 
na utilização da informação espectral de cada pixel de maneira individual, permitindo buscar as regiões homogêneas.

\section{Análise do Uso do Solo na Área de Influencia do Aeroporto Santa Genoveva}

Para coleta de dados primários foram utilizadas imagens de satélites de três anos diferentes, sendo uma delas, antes do início das obras em 2003 e com finalização em 2017. Foi considerado uma im-agem intermediária. Desse modo, consideraramse os anos de 2003, 2014 e 2017 e foram gerados os mapas temáticos. As imagens coletadas foram usadas para identificar o uso do solo local após a expansão do aeroporto Santa Genoveva. Assim, essas imagens, podem comprovar a alteração do uso do solo local no seu entorno, ou seja, o impacto do transporte aéreo sobre a região de estudo.

A classificação por meio do QGIS resultou em mapas temáticos com nítidas imagens. O que permite verificar as diferentes classes definidas. No entanto, o programa criou confusões no momento da classificação. Houve confusão entre o solo exposto e a área residencial por terem tons de cores muito parecidos. A mesma situação ocorreu entre a classe água e solo exposto, como por exemplo no mapa de 2003, que podem ser explicado pelo efeito de miragens, devido a reflexão da luz solar no momento em que o satélite capturou a imagem.

Ao analisar as imagens (Figuras 5, 6 e 7), percebe-se que no decorrer da obra de expansão houve um aumento de áreas construídas, principalmente as áreas industriais e/ou comerciais, com destaque à imagem mais recente, 2017, no qual a obra já está totalmente finalizada (Figura 7).

Observa-sequenãohouvemudanças visuaissignificativas nasáreas residenciais, como no caso dos setores: Setor Jaó, Jardim Guanabara, Vila dos Subtenentes e Sargentos, Santa Genoveva, Residencial Barravento e Setor Rasmussem, Residencial Ânglo que estão ao redor do aeroporto, pois são bairros que foram consolidados em 
questão de ocupação do solo há muito tempo. Uma observação interessante foi o aumento de área verde, principalmente nas proximidades do aeroporto que pode ser constatada na imagem (Figura 7).

No entorno do aeroporto houve um aumento no número de empresas que se instalaram; outras, no entanto que já existiam, sofreram ampliações. Pode-se dizer que uma das causas para esse aumento está ligado ao maior movimento da demanda do aeroporto e a proximidade de acesso do aeroporto a BR-153. Exatamente ao lado leste da rodovia citada, entre os bairros Barravento e Residencial Ânglo, também houve a instalação de algumas indústrias ligadas ao ramo logístico e de transportes como: Condomínio Logístico LOG Goiânia, Centro Oeste Express, Centro Oeste Entregas Rápidas, Grupo PHD, Braspress Transportes Urgentes, Asteróide Transportes, Tracbel. Além de empresas ligadas ao ramo alimentício como: CDCS Smart Goiânia, Distribuidora Prime Sete, Uvale Frutas Tropicais, L.A. Ferretti, Polpas de Frutas SeS. E também de bebidas como Distribuidora Prime Sete. Nesse mesmo período houve ainda a expansão da Cifarma Científica Farmacêutica, já existente em 2003.
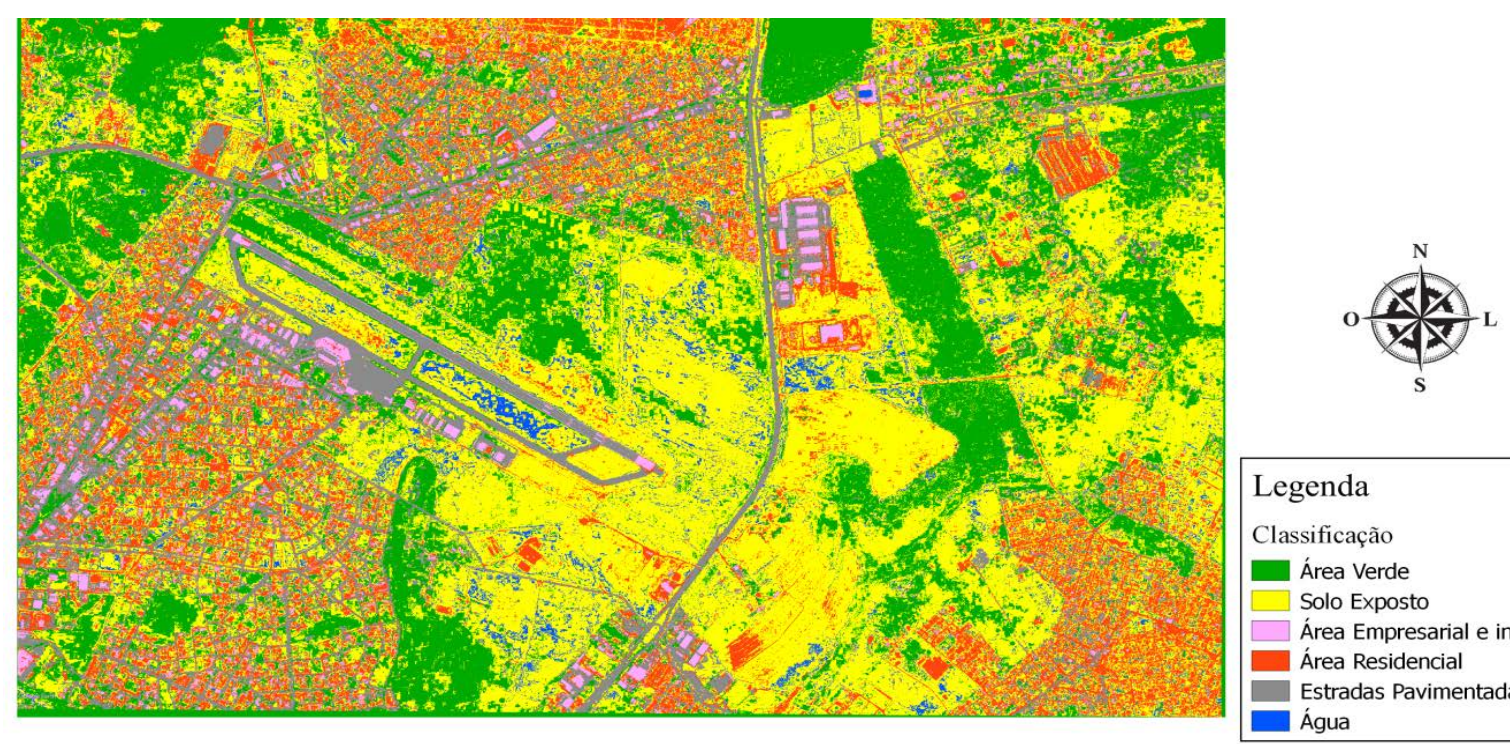

Legenda

Classificação

- Área Verde Solo Exposto

Área Empresarial e industria - Área Residencial Estradas Pavimentadas Água

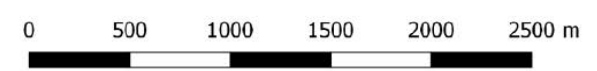

Figura 5 - Classificação MAXVER do Aeroporto Santa Genoveva e seu entorno - ano 2003. Fonte: os autores. 
Análise do Uso e Ocupação do Solo relacionado à Expansão do Aeroporto Internacional ...

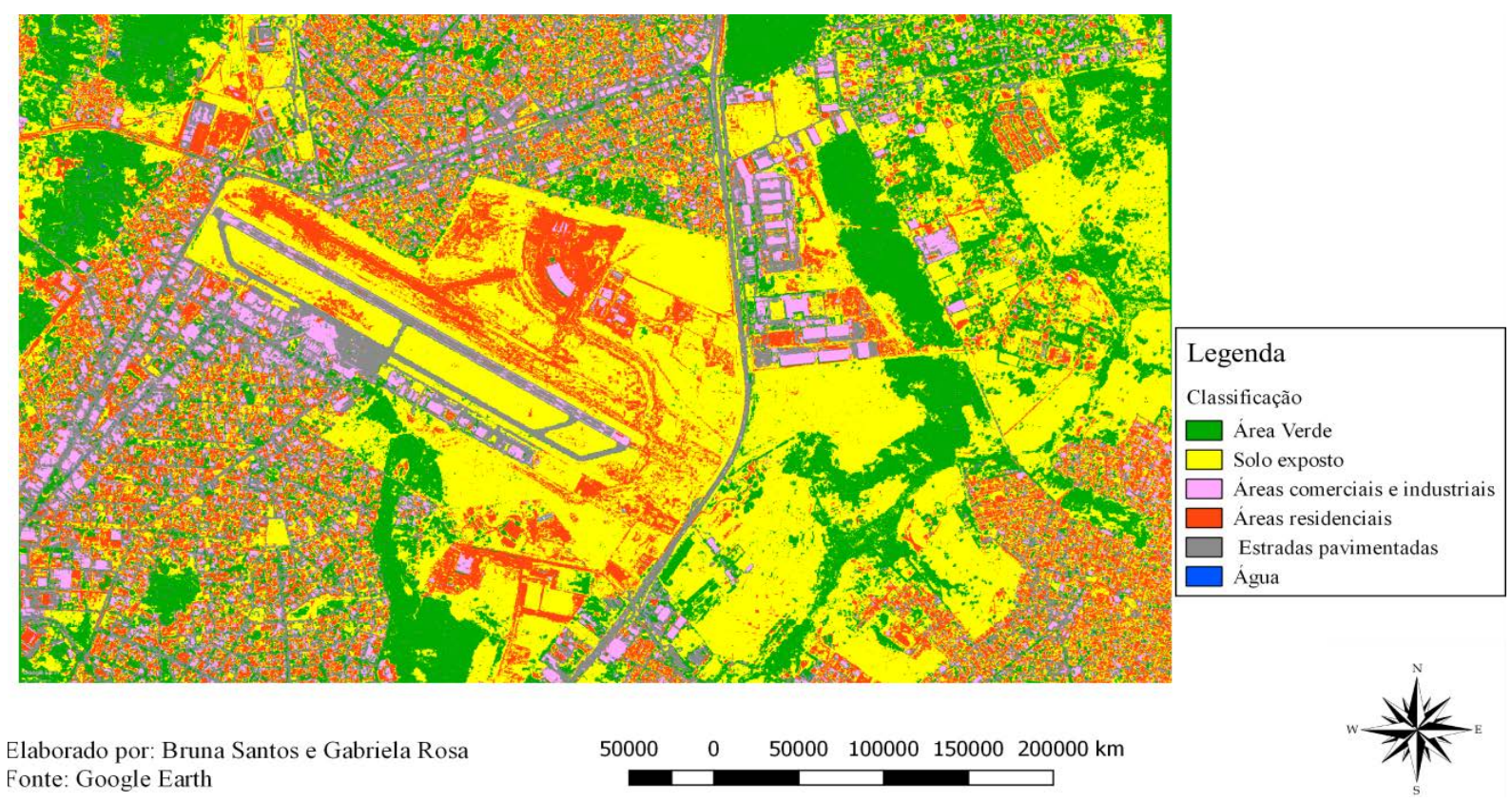

Figura 6 -Classificação MAXVER do Aeroporto Santa Genoveva e seu entorno - ano 2014. Fonte: os autores.

17
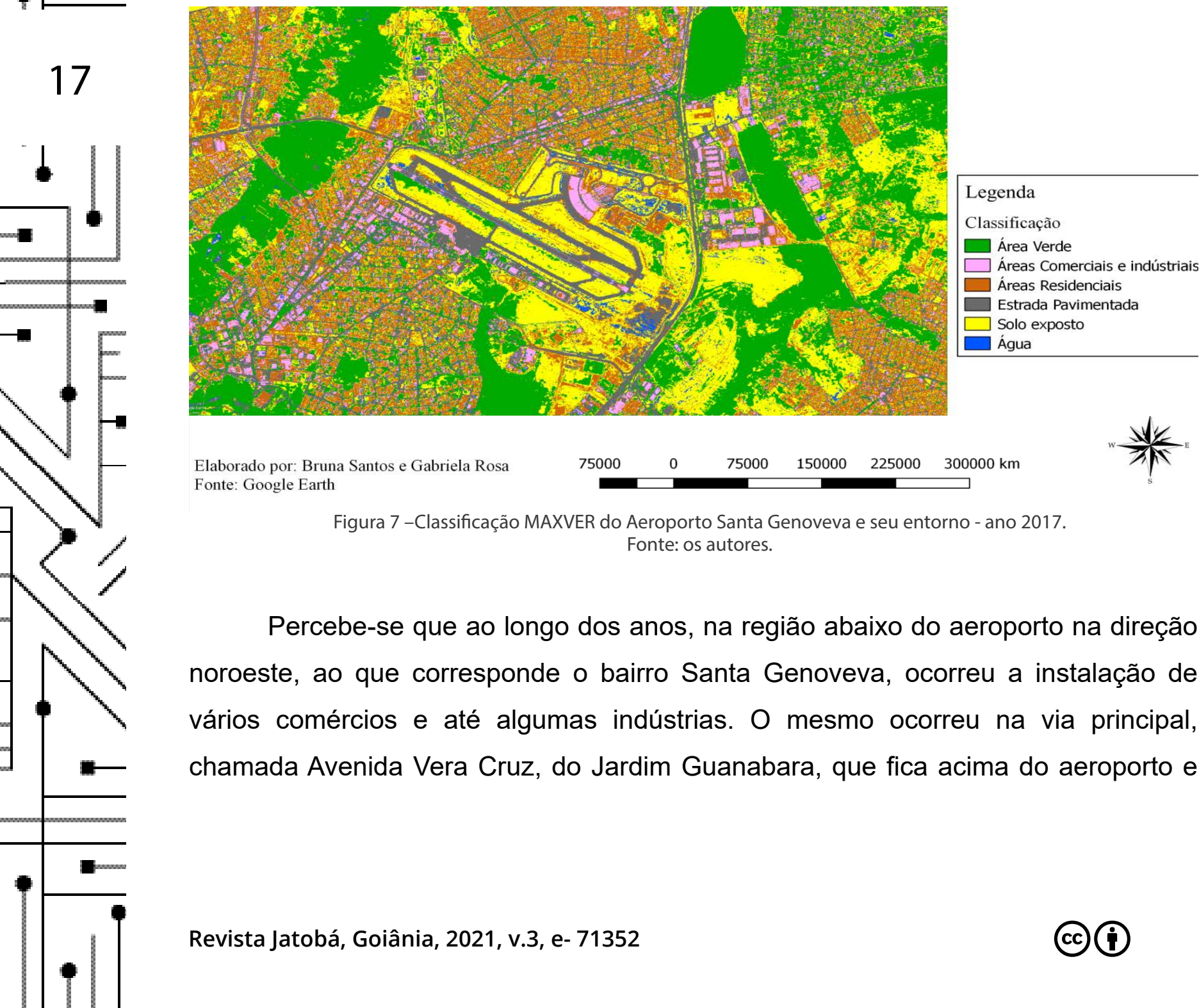
Fonte: Google Earth

Figura 7 -Classificação MAXVER do Aeroporto Santa Genoveva e seu entorno - ano 2017. Fonte: os autores.

Percebe-se que ao longo dos anos, na região abaixo do aeroporto na direção noroeste, ao que corresponde o bairro Santa Genoveva, ocorreu a instalação de vários comércios e até algumas indústrias. O mesmo ocorreu na via principal, chamada Avenida Vera Cruz, do Jardim Guanabara, que fica acima do aeroporto e 
liga diretamente o citado com a BR-153, como pode-se verificar nas Figuras 5, 6 e 7. Essa região encontra-se dentro da área de influência, citada anteriormente pela Lei Municipal de № 5212 (Prefeitura de Goiânia, 2018).

\section{Conclusões}

Ao realizar a classificação MAXVER para a análise do uso do solo da área de influência do aeropor-to Santa Genoveva, conclui-se que visualmente houve uma alteração no uso do solo. Assim, torna-se certa as afirmações de Fermisson et al (2004) sobre os quatro componentes que tratam da interação transporte e uso do solo. Dentre esses, principalmente o que afirma que alocação espacial das diferentes categorias de uso do solo por meio de instrumentos de ordenamento físico condiciona a localização de diversas atividades humanas no território. O que permite constatar que o transporte pode ser um instrumento de alteração do uso do solo.

O método indireto usado permite ser feita análise qualitativa por meio da comparação visual da do entorno aeroportuário. Os cortes temporais destacados na pesquisa mostraram-se eficazes e resultaram em imagens de boa resolução, possíveis de confirmar as evidências. Porém, torna-se im-portante quantificar as alterações que ocorreram temporalmente, trabalho que pode ser apontado para o desdobramento deste. Além dessa possibilidade, , é importante identificar as mudanças que ocorreram no uso do solo diretamente influenciados pela implantação do aeroporto por meio de um corte espacial mais detalhado no entorno aeroportuário, observando seus impactos diretos e indiretos.

\section{Referências}

ANAC (2007) Plano Aeroviário do Estado de São Paulo. V. 1. Agência Nacional de Aviação Civil, São Paulo, SP.

ANAC (2018) Declaração de Capacidade: 2018. Disponível em: <http://www. anac.gov.br/assuntos/setor-regulado/empresas/slot/aeroportos/GYN/declaracao- 
de-capacidade/sbgo_gyn_s18.pdf>. Goiânia: 2018. Acesso em 24 de abril de 2018. Agência Nacional de Aviação Civil

ANAC (2016) Portaria no 1141/GM5 de 08/12/1987. DOU No 187, S/1, 09/12/1987. Disponível em: <https://www.anac.gov.br/assuntos/legislacao/legislacao-1/portarias/ portarias-1987/portaria-no-1141-gm5-de-08-12-1987> Agência Nacional de Aviação Civil.

ANAC (2017) Plano Diretor. Disponível em: <http://www.anac.gov.br/assuntos/setorregulado/aerodromos/planejamento-aeroportuario/planos-diretores-aprovados/sbgo. pdf $>$. Acesso em 24 de abril de 2018. Agência Nacional de Aviação Civil.

ANAC (2019) Projeto de aeródromos. Regulamento Brasileiro da Aviação Civil RBAC $\mathrm{n}^{0}$ 154. Emenda $\mathrm{n}^{\circ} 06$ Disponível em: https://www.anac.gov.br/assuntos/legislacao/ legislacao-1/boletim-de-pessoal/2019/37s1/anexo-i-rbac-no-154-emenda-06. Agência Nacional de Aviação Civil.

ANAC (2021) Por dentro da aviação: Aeroportos - Entendendo como funciona o setor aéreo. Cartilha. Setembro, 21p. Agência Nacional de Aviação Civil.

ASHFORD, N. J.; MUMAYIZ, S. A.; WRIGHT, P. H. (2011) Airport Engineering Planning, Design and Development of 21 st-century airports. 4th. ed. New Jersey: John Wiley \& Sons Inc.

Aviação Brasil (2018) Aeroporto de Goiânia. Disponível em: <https://www. aviacaobrasil.com.br/aeroporto-de-goianiasanta-genoveva/> Acesso em: 13 de junho de 2018.

Campos, V. (2013) Planejamento de Transportes: conceitos e modelos. 1 ed. Interciência, Rio de Janeiro.

Congedo, Luca (2018) Semi-Automatic Classification Plugin Documentation: Versão 6.1.0.1. Disponível em: < https://fromgistors.blogspot.com/p/user-manual. html?spref=scp>. Acesso em 05 de julho de 2018.

FAA (2009) Order 5190.6B Airports - Chapter 20 Compatible Land Use and Airspace Protection.

Fermisson, J.; MACÁRIO, R.; CARVALHO, D. (2004) A Influência das interacções transportes-uso do solo nos padrões de mobilidade urbana: problemas e medidas. Lisboa, Portugal. 
Google (2018) Google Earth. Disponível em: < https://www.google.com/earth/>. Acesso em: 01 de julho de 2018.

Gomes, C.; Bayer, M. S. M. (2011) Interações entre Aeroporto, Cidade e Região: Desafios para uma ação a respeito do caso de São José dos Campos SP.

GÜLLER, M.; GÜLLER, M. (2001) From Airport to Airport City - GULLER. ARC: Airport Regions Conference, Barcelona.

Infraero (2018) Aeroporto de Goiânia - Santa Genoveva: Características. Disponível em: <http://www4.infraero.gov.br/aeroportos/aeroporto-de-goiania-santa-genoveva/ sobre-o- - aeroporto/caracteristicas/>. Acesso em 20 de abril de 2018. Empresa Brasileira de Infraestrutura Aeroportuária.

INFRAERO (2020). Aeroporto de Goiânia passa a ser Internacional. Disponível em: <https://www4.infraero.gov.br/imprensa/noticias/aeroporto-de-goiania-passa-aserinternacional-com-aprovacao-da-anac/>. Acesso em: 31 de agosto 2021.

JANIC, M. (2016) Analyzing, modeling, and assessing the performances of land use by airports. International Journal of Sustainable Transportation, [s. I.], v. 10, n. 8, p. 683-702.

KASARDA, J. D.; LINDSAY, G. (2012) Aerotrópole: o modo como viveremos no futuro. Tradução: Sieben Gruppe. São Paulo: DVS Editora.

Magalhães, M. T.; Aragão, J. J.G.; Yamashita, Y. (2014) Definição de transporte: uma reflexão sobre a natureza do fenômeno e objeto da pesquisa e ensino em transportes. Revista Transportes. V. 22. n. 2. Associação Nacional de Pesquisa e Ensino em Transportes.

Nigriello, A.; Pereira, A.; Metran, Jean (2002) Pontos de articulação. Revista dos Transportes Públicos. Ano $25-4^{\circ}$ trimestre. Associação Nacional de Transportes Públicos.

Pinto, J. C. S. (2012) Plano Diretor. Instituto Tecnológico de Aeronáutica. São Paulo, SP.

Prefeitura de Goiânia (2017) Plano diretor Goiânia do futuro. Goiânia, GO.

Prefeitura de Goiânia (2018) Lei Municipal de $\mathbf{N}^{\circ}$ 5212, de 22 de dezembro de 1976. Disponível em: < https://leismunicipais.com.br/a/go/g/goiania/leiordinaria/1976/521/5212/lei-ordinaria-n-5212-1976-criadas-as-seguintes-zonasespeciais> Acesso em 13 junho de 2018. 
Santos, L. (2015) Reaprendendo a relação entre transporte e Uso do solo - A importância da expansão dos transportes integrada ao desenvolvimento planejado das cidades. $21^{a}$ Semana de Tecnologia Metroferroviária. AEAMESP. São Paulo, SP.

RMTC (2018) Linha 313. Disponível em: <http://www.rmtcgoiania.com.br/ blog/2017/01/25/linha-313-passa-a-atender-o-aeroporto-de-goiania/>. Acesso em 22 de Abril de 2018. Rede Metropolitana de Transportes Coletivos de Goiânia, Goiânia, GO.

Walker, A.; Stevens, N. (2008). Airport city developments in Australia: Land use classification and analyses. 10th TRAIL Congress and Knowledge Market. The The Netherlands: Rotterdam 14-15 October.

\section{NOTAS}

\section{Publisher}

21 Universidade Federal de Goiás. Faculdade/Instituto/Escola. Programa de Pós-graduação Projeto e Cidade. Publicação no Portal de Periódicos UFG. As ideias expressadas neste artigo são de responsabilidade de seus autores, não representando, necessariamente, a opinião dos editores ou da universidade.

RECEBIDO EM: 01/11/2021

APROVADO EM: 24/12/2021

PUBLICADO EM: 30/12/2021 